\title{
Fermentative degradation of dipicolinic acid (pyridine-2,6-dicarboxylic acid) by a defined coculture of strictly anaerobic bacteria
}

\author{
Birgit Seyfried ${ }^{1} \&$ Bernhard Schink ${ }^{2, *}$ \\ Fakultät für Biologie, Universität Konstanz, Postfach 5560, D-7750 Konstanz, RFG; (present address: \\ ${ }^{1}$ Angewandte Mikrobiologie, Oberer Eselsberg M 23, D-7900 Ulm; ${ }^{2}$ Lehrstuhl Mikrobiologie I \\ der Eberhard-Karls-Universität, Auf der Morgenstelle 28, D-7400 Tübingen, RFG) (* requests for offprints)
}

Key words: dipicolinic acid, pyridine, heterocyclic aromatics, fermentation, nitrogen metabolism, Desulfuromonas acetoxidans

\begin{abstract}
Degradation of dipicolinic acid (pyridine-2,6-dicarboxylic acid) under strictly anaerobic conditions was studied in enrichment cultures from marine and freshwater sediments. In all cases, dipicolinic acid was completely degraded. From an enrichment culture from a marine sediment, a defined coculture of two bacteria was isolated. The dipicolinic acid-fermenting bacterium was a Gram-negative, non-sporeforming strictly anaerobic short rod which utilized dipicolinic acid as sole source of carbon, energy, and nitrogen, and fermented it to acetate, propionate, ammonia, and $2 \mathrm{CO}_{2}$. No other substrate was fermented. This bacterium could be cultivated only in coculture with another Gram-negative, non-sporeforming rod from the same enrichment culture which oxidized acetate to $\mathrm{CO}_{2}$ with fumarate, malate, or elemental sulfur as electron acceptor, similar to Desulfuromonas acetoxidans. Since this metabolic activity is not important in substrate degradation by the coculture, the basis of the dependence of the dipicolinic acid-degrading bacterium on the sulfur reducer may be sought in the assimilatory metabolism.
\end{abstract}

\section{Introduction}

Among the various types of aromatic compounds found in biological material, pyridine derivatives play a significant role, e.g., in the coenzymes NAD, NADP, and pyridoxal phosphate. Another pyridine derivative of interest is dipicolinic acid, a characteristic component of bacterial endospores. It amounts to $10-15 \%$ of the bacterial spore dry matter, and is excreted into the environment during spore germination (Schlegel 1985). It is synthesized in most sporeforming bacteria from pyruvate and aspartic semialdehyde in a side reaction of diaminopimelate and lysine biosynthesis (Zubay 1983).
Studies on aerobic bacteria able to degrade pyridine and pyridine derivatives began about 40 years ago (von Plotho 1948; Moore 1949). An oxygenasedependent pathway of pyridine degradation has been suggested for a Bacillus sp. (Watson \& Cain 1975) and Micrococcus luteus (Sims et al. 1986). Since the nitrogen atom in the pyridine nucleus polarizes the distribution of the mesomeric $\pi$-electron system and, with that, destabilizes the aromatic ring structure, also an oxygen-independent cleavage of pyridine appears to be possible. Such a degradation pathway including reduction and subsequent hydrolysis was described for a Nocardia sp. (Watson \& Cain 1975).

Carboxy substituents may decrease ring stability 
and render an oxygen-independent attack even easier. Oxygen-independent ring hydroxylations at the $\mathrm{C}$-atoms 2 or 6 occur during degradation of nicotinic acid (pyridine-3-carboxylic acid) and picolinic acid (pyridine-2-carboxylic acid) by aerobic bacteria (Dagley \& Johnson 1963; Hirschberg \& Ensign 1971; Tate \& Ensign 1974; Shukla 1984). In fermentative degradation of nicotinic acid (pyridine-3-carboxylic acid) by Clostridium barkeri, the first step is the introduction of a hydroxyl group from water to form 6-hydroxy nicotinic acid, followed by ring reduction and ring fission (Harary 1957; Tsai et al. 1966; Holcenberg \& Tsai 1969). Dipicolinic acid is degraded by aerobic bacteria such as Achromobacter sp. and Bacillus brevis (Arima \& Kobayashi 1962). The pathways are not yet completely understood; ring hydroxylation and ring fission appear to be catalyzed by oxygenase enzymes (Kobayashi \& Arima 1962; Shukla 1984).

Anaerobic degradation of dipicolinic acid has not yet been reported.

\section{Materials and methods}

\section{Sources of bacteria}

Enrichment cultures were inoculated with marine sediments from channels in Venice, Italy, freshwater sediments from a polluted creek near Konstanz, FRG, or digested sludge from the municipal sewage treatment plants at Konstanz and Göttingen, FRG.

\section{Cultivation}

All procedures for cultivation and isolation as well as all methods for analysis of metabolic products were essentially as described previously (Widdel \& Pfennig 1981; Schink \& Pfennig 1982). The bicarbonate-buffered, sulfide-reduced mineral medium contained trace element solution SL 10 (Widdel et al. 1983), selenite-tungstate solution (Tschech \& Pfennig 1984) and 7 water-soluble vitamins (Pfennig 1978). The $\mathrm{pH}$ was 7.2-7.4. Freshwater medium contained $1.0 \mathrm{~g} \mathrm{NaCl}$ and $0.4 \mathrm{~g} \mathrm{MgCl}_{2} \cdot 6 \mathrm{H}_{2} \mathrm{O}$, saltwater medium $20.0 \mathrm{~g} \mathrm{NaCl}$ and $3.0 \mathrm{~g} \mathrm{MgCl}_{2}$. $6 \mathrm{H}_{2} \mathrm{O}$ per 1 . Dipicolinic acid was added from a concentrated stock solution to $2 \mathrm{mM}$ final concentration. Pure cultures were isolated by repeated application of the agar shake dilution method (Pfennig 1978).

Purity of cultures was checked microscopically after growth in defined as well as in complex medium (AC-medium, Difco Laboratories, Detroit, Michigan, USA). All growth tests were carried out at least in duplicates at $28^{\circ} \mathrm{C}$.

Gram staining was carried out after Magee et al. (1975).

\section{Enzymes}

All enzyme activities were assayed with a Zeiss PM4 spectrophotometer at $25^{\circ} \mathrm{C}$ under strictly anaerobic conditions in modified Thunberg cuvettes. Cells were permeabilized in the respective assay cuvettes with cetyltrimethyl ammonium bromide (CTAB; details see Schink et al. 1987). Hydrogenase, acetaldehyde: ferredoxin oxidoreductase, and pyruvate: ferredoxin oxidoreductase were measured with benzylviologen as electron acceptor (Schink 1985; Odom \& Peck 1981), phosphotransacetylase and acetate kinase after Bergmeyer (1974), malate dehydrogenase and fumarase after Stams et al. (1984), succinate dehydrogenase after Boonstra et al. (1975), propionyl CoA: succinate CoA transferase after Hilpert et al. (1984), lactate dehydrogenase after Bergmeyer (1974) and Stams \& Hansen (1982).

\section{Chemical analyses}

Dipicolinic acid was quantified by its absorption spectrum taken in a $50 \mathrm{mM}$ potassium phosphate buffer, pH 7.0 , at $200-350 \mathrm{~nm}$ wavelength with a Shimadzu UV 300 spectrophotometer. Volatile fermentation products were assayed by gas chromatography (Schink \& Pfennig 1982), succinate as dimethyl ester by capillary gas chromatography (Dehning \& Schink 1989). Protein was quantified after Kuenen \& Veldkamp (1972). 


\section{Chemicals}

All chemicals were of reagent grade quality and obtained from E. Merck, Darmstadt, and Fluka, Neu-Ulm, FRG. Biochemicals and enzymes were purchased from Sigma, München, and Boehringer, Mannheim, FRG.

\section{Results}

Enrichment, isolation and cytological characterization

$50 \mathrm{ml}$-enrichment cultures with $2 \mathrm{mM}$ dipicolinic acid in either freshwater or saltwater medium were inoculated each with $5 \mathrm{ml}$ of anoxic sludge or sediment samples from various habitats. Gas production started after 2-4 weeks, with sediment from Canal Grande, Venice, after 1 week. Cultures were transferred into fresh medium after further 2 weeks, and later on as soon as turbidity developed. After 4-5 transfers, methane production ceased and acetate and propionate were identified as fermentation products.

In freshwater cultures, the predominant cells were very small, motile, coccoid short rods. In marine enrichments, longer motile rods predominated. Isolation was attempted in agar shake dilution series. After about 2 weeks of incubation, small, creamy-to-orange-coloured lens-shaped colonies became visible which contained the cell types observed in the corresponding liquid enrichment cultures. Colonies from freshwater cultures did not grow again in liquid medium, even if yeast extract, rumen fluid, or $0.1 \%$ agar was added. These cultures were discarded after numerous trials. From the marine enrichments, two cultures (GraDip1 from Canal Grande sediment, MaDip1 from another channel sediment from Venice, Italy) were isolated each of which consisted of two types of bacteria. Culture GraDip1 was further characterized.

A phase contrast photomicrograph of this culture is shown in Fig. 1a. Two different types of short rods are visible, the one only in small numbers and slightly thinner than the other one. Several attempts were made to separate the two cell
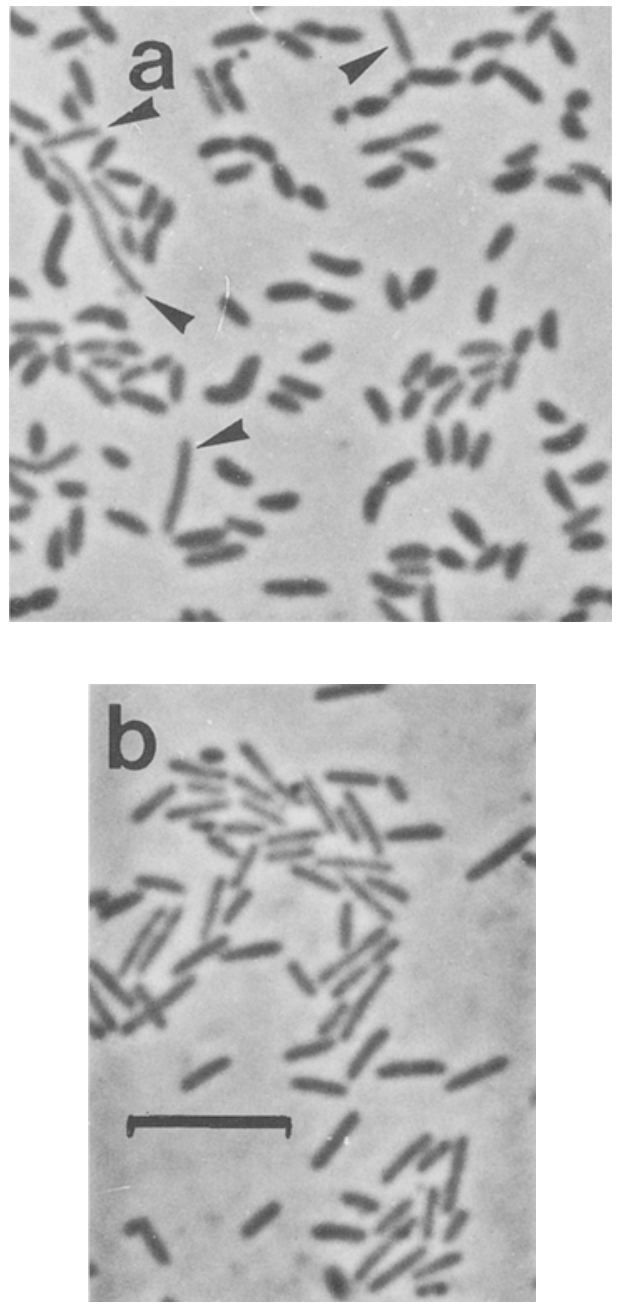

Fig. 1. Phase contrast photomicrograph of isolated cultures. (a) Mixed culture GraDip1 consisting of two cell types. Arrows point at thinner rods. (b) Strain AF isolated from culture GraDip1 (thinner rod). Bar equals $5 \mu \mathrm{m}$ for both pictures.

types. Finally, the thinner rod (strain AF) could be grown in pure culture with acetate and fumarate as substrates. These cells were motile, Gram-negative thin rods with round ends, $0.3-0.5 \times 1.8-3.5 \mu \mathrm{m}$ in size (Fig. 1b). It oxidized acetate to $\mathrm{CO}_{2}$ with either fumarate, L-malate, or elemental sulfur as electron acceptor. Succinate, propionate or dipicolinic acid was not oxidized; sulfate, thiosulfate or sulfite was not reduced. Colonies were orange to pink coloured due to high cytochrome contents. With these properties, strain AF resembled Desulfuromonas acetoxidans (Pfennig \& Biebl 1976). It was not 
characterized any further. The predominant, dipicolinic acid-degrading cells were motile, short, straight rods with slightly pointed ends, $0.6-0.7 \times$ $1.5-2.5 \mu \mathrm{m}$ in size (Fig. 1a). The Gram reaction after staining was negative; neither capsules nor spores were detected.

All attempts to grow these bacteria in pure culture independent of strain AF failed, no matter whether yeast extract, yeast extract-peptone digest, fatty acid mixtures or sterilized culture supernatant from pregrown GraDip1 cultures were added to the dipicolinate-containing mineral medium.

\section{Physiology}

The mixed culture GraDip1 was used for all further experiments. It was strictly anaerobic; no growth was found under aerobic or microaerobic conditions in soft agar gradients. It grew best in the marine medium used for isolation; with lower salt concentrations, growth was considerably slower. Phosphate concentrations higher than $1.5 \mathrm{mM}$ retarded growth; no growth occurred in the presence of $10 \mathrm{mM}$ phosphate. Addition of selenite $(5 \times$ $10^{-8} \mathrm{M}$ ) did not enhance growth. Pyridoxamin and thiamin were the only vitamins required. Yeast extract or other undefined medium additions were not needed and did not enhance growth at all. Dipicolinic acid served as nitrogen source in ammonia-free medium.

Out of a great variety of substrates, only dipicolinic acid was degraded. No growth was found with pyridine $(0.5 \mathrm{mM})$; picolinic acid, nicotinic acid, pyridine-3,5-dicarboxylic acid, 2-, 3-, and 4hydroxypyridine, 4-hydroxydipicolinic acid, purine, pyrimidine, uric acid, fructose, glucose (each $2 \mathrm{mM}$ ); methanol, ethanol, xylose, arabinose (each $5 \mathrm{mM}$ ); malonate, acetoin, ethylene glycol, 2,3butanediol, lactate, malate, fumarate, aspartate, pyruvate, citrate, glycolate, glycerate, tartrate, glutarate*, succinate*, glycerol* ${ }^{*}$ glycine + alanine, alanine + pyruvate (each $10 \mathrm{mM}$ ); yeast extract, casamino acids $(0.1 \% \mathrm{w} / \mathrm{v})$. Substrates with * were tested in the presence of $5 \mathrm{mM}$ acetate. Neither nitrate, sulfate, sulfite, or thiosulfate was reduced. The maximum growth rate was $0.046 \mathrm{~h}^{-1}$ (minimum doubling time $15 \mathrm{~h}$ ) at $28^{\circ} \mathrm{C}$ and $\mathrm{pH}$ 7.2-7.4. No growth occurred below $20^{\circ} \mathrm{C}$ or above $34^{\circ} \mathrm{C}$; the $\mathrm{pH}$ limits were $\mathrm{pH} 6.5$ and $\mathrm{pH} 8.5$.

In Figure 2, dipicolinate-dependent growth of the defined mixed culture GraDip1 is shown. The substrate was added at intervals of 2 days at increments of $2 \mathrm{mM}$ each because higher substrate additions inhibited growth. Acetate and propionate were formed stoichiometrically from dipicolinic acid, acetate slightly less than propionate. From the data, an empirical fermentation equation was derived as follows:

$1 \mathrm{mmol}$ dipicolinate $\rightarrow 0.98 \mathrm{mmol}$ propionate + $0.81 \mathrm{mmol}$ acetate $+0.86 \mathrm{mmol}$ ammonia + $11.1 \mathrm{mg}$ cell dry matter

The yield of dry cell matter varied between 10.3 and $11.7 \mathrm{~g}$ per mol dipicolinic acid. According to the formula

$$
\begin{aligned}
& 17 \mathrm{C}_{2} \mathrm{H}_{4} \mathrm{O}_{2}+8 \mathrm{NH}_{3} \rightarrow 8<\mathrm{C}_{4} \mathrm{H}_{8} \mathrm{O}_{2} \mathrm{~N}> \\
& +2 \mathrm{CO}_{2}+14 \mathrm{H}_{2} \mathrm{O}
\end{aligned}
$$

the amounts of acetate and ammonia converted into cell material can be calculated $(20.8 \mu \mathrm{mol}$ acetate and $9.8 \mu \mathrm{mol} \mathrm{NH}_{3}$ per $\mathrm{mg}$ cell material). With this, the electron balance of the empirical equation above comes to $100.5 \%$.

In the presence of elemental sulfur, fumarate, or L-malate, the acetate formed from dipicolinic acid was oxidized to $\mathrm{CO}_{2}$ and the number of the thin rods (strain $\mathrm{AF}$ ) increased considerably.

\section{Enzymes}

Enzyme activities were assayed with permeabilized cells of the dipicolinate-grown coculture in which the sulfur-reducing bacterium amounted to about $2 \%$ of total biomass as judged from the microscopic picture of the culture. High or intermediate activities were found for the following enzymes (in $\mu \mathrm{mol}$ substrate converted per min and g protein): pyruvate: ferredoxin oxidoreductase, 400; acetaldehyde: ferredoxin oxidoreductase, 35; acetate kinase, 275; phosphotransacetylase, 75 . No activity 


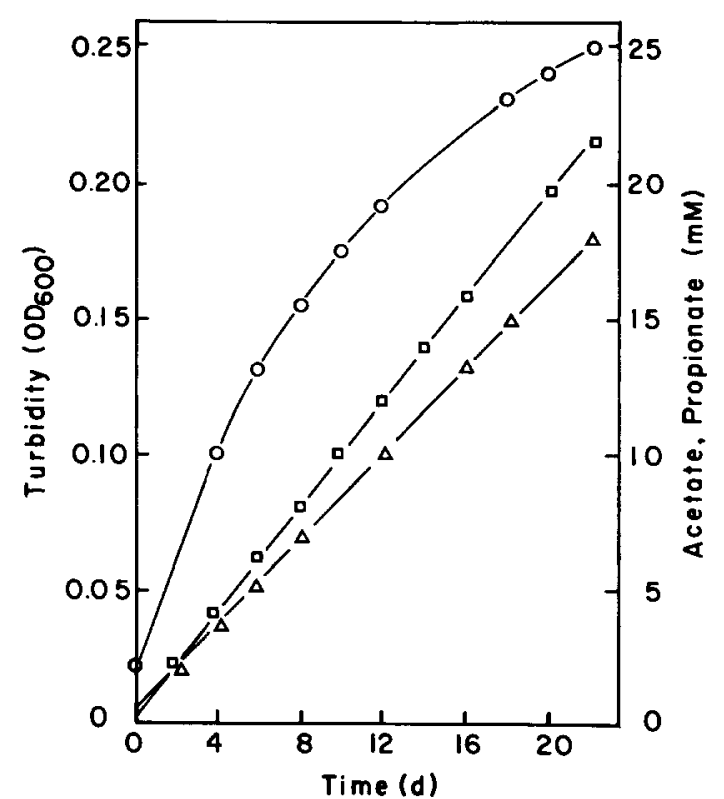

Fig. 2. Growth and product formation from dipicolinate by the coculture GraDip1. $2 \mathrm{mM}$ dipicolinate was provided at 2 days intervals. (O) Optical density at $600 \mathrm{~nm}$ wavelength, $(\square)$ Propionate formed, $(\Delta)$ acetate formed.

( $<5.0 \mathrm{U}$ per g protein) was found for the following enzymes: hydrogenase (benzylviologen-dependent), malate dehydrogenase, fumarase, fumarate reductase, propionyl-CoA: succinate $\mathrm{CoA}$ transferase, lactate dehydrogenase.

\section{Discussion}

\section{Anaerobic degradation of dipicolinic acid}

The defined coculture described in this study ferments dipicolinic acid stoichiometrically to acetate, propionate, ammonia, and carbon dioxide, according to the equation

$$
\begin{aligned}
& \mathrm{C}_{5} \mathrm{H}_{3} \mathrm{~N}(\mathrm{COO})_{2}{ }^{2-}+4 \mathrm{H}_{2} \mathrm{O}+\mathrm{H}^{+} \rightarrow \\
& \mathrm{CH}_{3} \mathrm{COO}^{-}+\mathrm{CH}_{3} \mathrm{CH}_{2} \mathrm{COO}^{-}+\mathrm{NH}_{4}{ }^{+}+ \\
& 2 \mathrm{CO}_{2} \\
& \triangle \mathrm{G}_{0}{ }^{\prime}=-125 \mathrm{~kJ} \text { per mol dipicolinate }
\end{aligned}
$$

The free energy change was calculated after published tables (Thauer et al. 1977). The dipicolinatefermenting bacterium which was isolated in de-
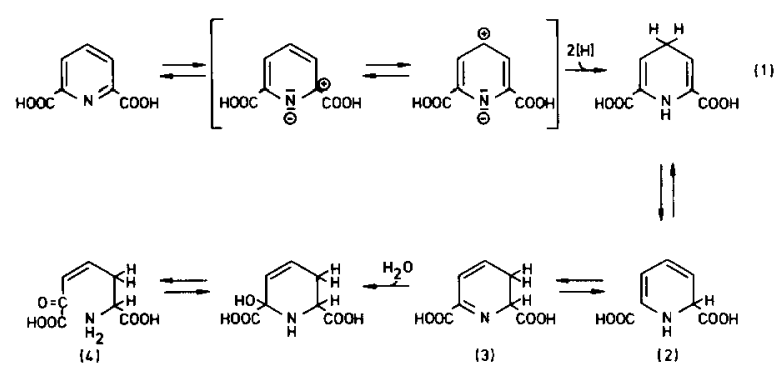

Fig. 3. Hypothetical initial reactions in anaerobic dipicolinate degradation by our coculture. Explanations in the text.

fined coculture with an acetate-oxidizing sulfurreducing bacterium appears to be highly specialized on this substrate only; no other substrates for degradation could be found.

The pathway of dipicolinate degradation by our culture GraDip1 cannot involve oxygenase reactions as this was described for aerobic dipicolinate degradation (Kobayashi \& Arima 1962). Since the two carboxylic groups vicinal to the pyridine nitrogen atom help to intensify the positive partial charge of the $\mathrm{C}$-atoms 2, 4, and 6(Fig. 3), reduction to dihydrodipicolinic acid $(1,2)$ and tautomerization to (3) should be at least as easy as with pyridine itself. Water addition allows finally cleavage to 2-amino-6-oxo-hex-4-enedioic acid (4) which, after water addition, would yield pyruvate and aspartic semialdehyde, thus reverting the dipicolinate synthesis reaction sequence (Zubay 1983). Aspartic semialdehyde would finally lead to propionate; the aldehyde dehydrogenase activity detected in our cells with acetaldehyde as substrate might be a side activity of the aldehyde dehydrogenase involved in this reaction series. Whether aspartic semialdehyde is converted to propionate via the methylmalonylCoA pathway or the 2-hydroxyglutarate pathway (Wegener et al. 1968) has still to be elucidated, our preliminary enzyme measurements do not yet allow conclusive decisions. Pyruvate takes its usual path via pyruvate: ferredoxin oxidoreductase, phosphotransacetylase and acetate kinase to acetate, thus yielding 1 ATP per dipicolinate degraded. This ATP yield would agree well with the measured cell yield (10-11 g/mol; see Stouthamer 1979) but it cannot be excluded yet that the conversion of aspartic semialdehyde to propionate could synthe- 
size further ATP fractions, e.g., in fumarate reduction.

Pyruvate oxidation yields low-potential electrons which are transferred to a ferredoxin-like electron carrier. These electrons are probably needed for the initial reduction of dipicolinic acid to dihydrodipicolinic acid. The analogous reduction of 6-hydroxynicotinic acid by Clostridium barkeri is coupled with ferredoxin as well (Holcenberg \& Tsai 1969). It is understandable, therefore, that our bacterium cannot release these electrons as molecular hydrogen, and that we did not find benzyl viologen-dependent hydrogenase activity.

The suggested pathway would also explain why dipicolinate degradation by our culture, contrary to nicotinic acid degradation by Clostridium barkeri (Imhoff \& Andreesen 1979) was independent of selenite additions: attack on the C-atom 2 of dihydrodipicolinate by a weak nucleophile like water is chemically by far easier than with the C-atom 2 of nicotinic acid, and probably does not need a selenium enzyme, therefore.

\section{Assimilatory metabolism}

The empirical fermentation equation in the ' $\mathrm{Re}$ sults' section differs from the theoretical one above mainly in the amount of acetate formed. As shown in the 'Results' section, the gap in acetate formation is covered exactly by the amount of cell matter formed; cell matter is formed exclusively from the acetate residue, not at all from the propionate residue. This requires that part of the acetate is oxidized to $\mathrm{CO}_{2}$ to provide electrons, mainly for reductive carboxylation of acetyl-CoA to pyruvate and further to sugars and their derivatives. Fermenting bacteria usually cannot oxidize acetate; this ability has so far been demonstrated among the strict anaerobes only in sulfate- or sulfur-reducing as well as homoacetogenic bacteria (Thauer 1988). Lack of an acetate-oxidizing enzyme system may be the reason why our dipicolinate fermenter cannot be cultivated without small amounts of the acetate-oxidizing Desulfuromonas strain AF. This bacterium may run its energy metabolism on acetate and small amounts of elemental sulfur which always occur in sulfide-reduced media; its important function for the dipicolinate degrader may be to provide electrons for reductive acetate assimilation. At present, we do not know in which form these electrons are being transferred; hydrogen is probably not involved because our culture did not show hydrogenase activity. Further studies are needed to understand better the nature of this relationship between these two types of bacteria.

\section{Acknowledgement}

The authors are indebted to Prof. Dr N. Pfennig for support and valuable discussions, and to Carola Matthies for ammonia determination. Thanks are also due to Prof. Dr J Andreesen for helpful suggestions and literature hints, as well as to Prof. Dr W. Pfleiderer, Konstanz, for help in understanding the chemistry of the pyridine nucleus.

\section{References}

Arima K, Kobayashi Y (1962) Bacterial oxidation of dipicolinic acid. I. Isolation of microorganisms, their culture conditions, and end products. J Bacteriol 84: 759-764

Bergmeyer HU (1974) Methoden der enzymatischen Analyse. 3rd ed., Verlag Chemie, Weinheim

Boonstra J, Huttunen MT \& Konings WN (1975) Anaerobic transport in Escherichia coli membrane vesicles. J Biol Chem 250: 6792-6798

Dagley S \& Johnson PA (1963) Microbial oxidation of kynurenic, xanthurenic and picolinic acid. Biochim Biophys Acta 78 $577-587$

Dehning I \& Schink B (1989) Malonomonas rubra gen. nov. sp. nov., a microaerotolerant anaerobic bacterium growing by decarboxylation of malonate. Arch Microbiol 151: 427-433

Harary J (1957) Bacterial fermentation of nicotinic acid. II. Anaerobic reversible hydroxylation of nicotinic acid to 6hydroxynicotinic acid. J Biol Chem 227: 823-831

Hilpert W, Schink B \& Dimroth P (1984) Life by a new decarboxylation-dependent energy conservation mechanism with $\mathrm{Na}^{+}$as a coupling ion. EMBO J 3: 1665-1670

Hirschberg R \& Ensign JC (1971) Oxidation of nicotinic acid by a Bacillus species: purification and properties of nicotinic acid and 6-hydroxynicotinic acid hydroxylases. J Bacteriol 108: 751-756

Holcenberg JS \& Tsai L (1969) Nicotinic acid metabolism. IV. Ferredoxin-dependent reduction of 6-hydroxynicotinic acid 
to 6-oxo-1,4,5,6-tetrahydronicotinic acid. J Biol Chem 244: 1204-1211

Imhoff D \& Andreesen JR (1979) Nicotinic acid hydroxylase from Clostridium barkeri: Selenium-dependent formation of active enzyme. FEMS Microbiol Lett 5: 155-158

Kobayashi Y \& Arima K (1962) Bacterial oxidation of dipicolinic acid. II. Identification of $\alpha$-ketoglutaric acid and 3-hydroxydipicolinic acid and some properties of cell-free extracts. $J$ Bacteriol 84: 765-771

Kuenen JG \& Veldkamp H (1972) Thiomicrospira pelophila nov. gen., nov. sp., a new obligately chemolithotrophic colourless sulfur bacterium. Antonie van Leeuwenhoek J Microbiol Serol 38: 241-256

Magee CM, Rodeheaver G, Edgerton MT \& Edlich RF (1975) A more reliable Gram staining technic for diagnosis of surgical infections. Am J Surg 130: 341-346

Moore FW (1949) The utilization of pyridine by microorganisms. J Gen Microbiol 3: 143-147

Odom JM \& Peck HD (1981) Localization of dehydrogenases, reductases and electron transfer components in the sulfatereducing bacterium Desulfovibrio gigas. J Bacteriol 147: 161169

Pfennig N (1978) Rhodocyclus purpureus gen. nov. and sp. nov., a ring-shaped, vitamin $B_{12}$-requiring member of the family Rhodospirillaceae. Int J Syst Bacteriol 28: 283-288

Pfennig N \& Biebl H (1976) Desulfuromonas acetoxidans gen. nov. and sp. nov., a new anaerobic sulfur-reducing, acetateoxidizing bacterium. Arch Microbiol 110: 3-12

Schink B (1985) Fermentation of acetylene by an obligate anaerobe, Pelobacter acetylenicus sp. nov. Arch Microbiol 142: 295-301

Schink B \& Pfennig N (1982) Propionigenium modestum gen. nov. sp. nov., a new strictly anaerobic, nonsporing bacterium growing on succinate. Arch Microbiol 133: 209-216

Schink B, Kremer DR \& Hansen TA (1987) Pathway of propionate formation from ethanol in Pelobacter propionicus. Arch Microbiol 147: 321-327

Schlegel HG (1985) Allgemeine Mikrobiologie. 6th ed. Thieme Stuttgart

Shukla OP (1984) Microbial transformation of pyridine derivatives. J Sci Indust Res 43: 98-116

Sims GK, Sommers LE \& Konopka A (1986) Degradation of pyridine by Micrococcus luteus isolated from soil. Appl Environ Microbiol 51: 963-968

Stams AJM \& Hansen TA (1982) Oxygen labile L(+)lactate dehydrogenase activity in Desulfovibrio desulfuricans. FEMS Microbiol Lett 13: 389-394

Stams AJM, Kremer DR, Nicolay K, Weenk GH \& Hansen TA (1984) Pathway of propionate formation in Desulfobulbus propionicus. Arch Microbiol 139: 167-173

Stouthamer AH (1979) The search for correlation between theoretical and experimental growth yields. In: Quayle JR (Ed) International Review of Biochemistry, Microbial Biochemistry, Vol 21 (pp 1-47). University Park Press, Baltimore

Tate RL \& Ensign JC (1974) A new species of Arthrobacter which degrades picolinic acid. Can J Microbiol 20: 691-694

Thauer RK (1988) Citric-acid cycle, 50 years on. Modifications and an alternative pathway in anaerobic bacteria. Eur J Biochem 176: 497-508

Thauer RK, Jungermann K \& Decker K (1977) Energy conservation in chemotrophic anaerobic bacteria. Bacteriol Rev 41: 100-180

Tsai L, Pastan I \& Stadtman ER (1966) Nicotinic acid metabolism. II. The isolation and characterization of intermediates in the fermentation of nicotinic acid. J Biol Chem 241: 18071813

Tschech A, Pfennig N (1984) Growth yield increase linked to caffeate reduction in Acetobacterium woodii. Arch Microbiol 137: 163-197

Von Plotho O (1948) Untersuchungen an Proactinomyceten. Arch Mikrobiol 14: 12-45

Watson GK \& Cain RB (1975) Microbial metabolism of the pyridine ring. Metabolic pathways of pyridine biodegradation by soil bacteria. Biochem $J 146: 157-172$

Wegener WS, Reeves HC, Rabin R \& Ajl SJ (1968) Alternate pathways of metabolism of short-chain fatty acids. Bacteriol Rev 32: 1-26

Widdel F \& Pfennig N (1981) Studies on dissimilatory sulfatereducing bacteria that decompose fatty acids. I. Isolation of new sulfate-reducing bacteria enriched with acetate from saline environments. Description of Desulfobacter postgatei gen. nov. spec. nov. Arch Microbiol 129: 395-400

Widdel F, Kohring GW \& Mayer F (1983) Studies on dissimilatory sulfate-reducing bacteria that decompose fatty acids. III. Characterization of the filamentous gliding Desulfonema limicola gen. nov. sp. nov., and Desulfonema magnum sp. nov. Arch Microbiol 134: 286-294

Zubay G (1983) Biochemistry. Benjamin/Cummings Publ Co, Menlo Park, California 